\title{
A reorganização dos serviços de saúde no cenário local
}

\author{
The health care reorganization at the local level
}

Giselle Lavinas Monnerat 1

Mônica de Castro Maia Senna 2

Rosimary Gonçalves de Souza 1

${ }^{1}$ Faculdade de Serviço Social da UERJ. Rua São Francisco Xavier, $524 / 8$ o, bloco $\mathrm{F}$ Maracanã 20550-013 Rio de Janeiro RJ. giselle@uerj.br 2 Escola de Serviço Social da Universidade Federal Fluminense.
Abstract This paper aims to analyze as the local governments answer, in the decentralization context of the Brazilian State, to the new demands in order to the implementation and administration of the social policies. One focuses the health policies, where the local sphere is central inside the sectorial reform in course since the early nineties. The text ask the effective capacity of the Brazilian municipal districts exercise, in fact, its autonomy to elaborate and to execute policies, vis-à-vis the Brazilian local political tradition and the inequalities economic, social and regional characteristics of the country. We took the municipal district of São Gonçalo, in the metropolitan area of Rio de Janeiro, as analysis locus, looking for measure the impact provoked by the decentralization in the reorganization of the health services system. One consider the composition of the services in terms of the amount and quality, as well as of the reference and against-reference pattern among the attendance levels of the local health system. (One observed that the production of the health policy in that place collides against the limits characterized by the relationship among intrinsic elements to the own organization of the local health system and the way as it conforms to the political power in the municipal district). Key words Health policy, Decentralization, Local power, Health services organization
Resumo Este artigo tem por objetivo analisar como os governos locais vêm, no contexto da descentralização do Estado brasileiro, respondendo às novas exigências relativas à implementação e gestão das políticas sociais. Destaca-se o caso da política de saúde, cuja centralidade da esfera local se consolida pari passu ao aprofundamento da reforma setorial em curso a partir dos anos 90. O texto problematiza a capacidade efetiva de os municípios brasileiros exercerem, de fato, a sua autonomia para elaborar e executar politicas, vis-à-vis à tradição política local brasileira e as desigualdades econômicas, sociais e regionais características do país. Tomamos o município de São Gonçalo, na região metropolitana do Rio de Janeiro, como lócus de análise, buscando dimensionar o impacto da descentralização na reorganização da rede de serviços, a partir da composição dos serviços em termos da quantidade e qualidade da oferta de cuidados, bem como do padrão de referência e contra-referência entre os níveis de assistência do sistema local de saúde. (Observa-se que a produção da política de saúde nessa localidade esbarra em constrangimentos caracterizados pela interconexão entre elementos intrínsecos ao próprio ordenamento do sistema local de saúde e a maneira como se conforma o poder político no município).

Palavras-chave Politica de saúde, Descentralização, Poder local, Organização de serviços 


\section{Introdução}

Este artigo tem por objetivo realizar uma incursão sobre a natureza do poder local e suas virtualidades atuais, destacando especificamente a relação entre poder local e políticas sociais, em especial a política de saúde.

$\mathrm{Na}$ atualidade se reconhece que há um reforço generalizado da gestão política no próprio espaço local. No campo específico da política de saúde, está em andamento um processo que aponta francamente para a ampliação da capacidade decisória do governo e da sociedade locais. Neste contexto, é preciso lançar luz sobre o modo como - em meio a transformações fundantes de caráter global e, no nosso caso, também nacional - o espaço local vem desempenhando esse novo papel que lhe é atribuído.

No entanto, o dimensionamento do novo desenho adquirido pelos espaços locais, hoje depositários de grandes responsabilidades políticas, impõe a necessidade de estudos que tenham por objeto análises territorialmente localizadas.

No campo específico da política de saúde, é consenso entre os pesquisadores da área a valiosa contribuição dos estudos de caso, em razão da heterogeneidade de experiências que dão contornos singulares ao processo de implantação da política de saúde nas diversas regiões e municípios brasileiros.

Esta análise é fruto de uma pesquisa mais ampla que envolveu três instituições de ensino e pesquisa (Uerj, UFF e ENSP/Fiocruz), cujo objetivo foi analisar a gestão descentralizada da política de saúde em municípios da região metropolitana do Rio de Janeiro.

No contexto da realização da pesquisa, o caso de São Gonçalo se destaca como um casoexemplo expressivo para se analisar a relação entre poder local e política de saúde. Trata-se de uma localidade que conjuga um porte populacional considerável com índices de pobreza e déficit de estrutura urbana importante e que, recentemente, aderiu de forma peculiar, e por que não dizer audaciosa, ao Programa Saúde da Família, em um contexto onde os arranjos entre diversas instituições e atores são marcados pela persistência de tradições culturais clientelísticas na conformação do poder local.

A análise de como a instância de governo local vem respondendo às novas exigências postas ao desenvolvimento e gestão da política de saúde fomenta indagações relevantes sobre o imbricamento entre os marcos institucionais atuais da política formulada para o setor e as retraduções no plano da sua implementação, potencializadas ou limitadas pelo perfil do poder político em cada caso específico.

\section{Pacto federativo e políticas sociais no Brasil}

No caso brasileiro, duas ordens de questões marcam recorrentemente a literatura voltada para o poder local. A primeira diz respeito ao reconhecimento de que se tem vivido ao longo da história brasileira uma tensão permanente entre localismo e centralismo, na qual esses dois formatos de ordenação do poder político se alternam (com predominância do centralismo) e, ao mesmo tempo, constituem tema permanente de debate entre juristas, intelectuais, políticos, movimentos organizados e outros atores políticos (Abrucio, 1996; Daniel, 1990; Zimmermann, 1999).

A segunda ordem de questões refere-se ao intenso debate sobre a capacidade efetiva dos municípios brasileiros exercerem de fato a sua autonomia para elaborar e executar políticas voltadas a seu território correspondente. Um traço característico da realidade brasileira que alimenta este debate refere-se às fortes desigualdades econômicas, sociais e regionais do país, que têm, obviamente, reflexos na heterogeneidade dos governos locais entre nós (Arretche, 1999; Almeida, 1996; Abrucio, 1996; Bezerra: 1999; Rezende, 1997; Souza e Blumm, 1999).

Neste sentido, teorias e conceitos elaborados sobre a problemática local em contextos mais homogêneos (como países da Europa e da América do Norte) têm uma eficácia explicativa relativa para a compreensão do caso brasileiro, iluminando apenas alguns de seus aspectos. Daí se deriva a necessidade da realização de estudos interpretativos sobre a natureza e implicações do poder local no Brasil, o qual comporta, em função das diferenças que marcam o país, inúmeras modalidades de exercício deste poder, conforme as características regionais e locais no seu entrecruzamento com os traços constitutivos do perfil político nacional.

A intensificação das análises focalizando o poder local nos últimos anos está intimamente relacionada ao processo de descentralização do Estado, em curso desde o início da década de 1990. A maior divisão de responsabilidades entre as esferas de governo passa a ser uma norma tanto no tocante ao incentivo a uma ação mais 
efetiva dos níveis subnacionais de governo na criação de mecanismos que favoreçam o desenvolvimento econômico regional e local - mormente os incentivos fiscais e criação de infra-estrutura -, quanto no tocante à gestão de políticas de cunho social.

No que tange ao encaminhamento de políticas que fomentem a dinâmica econômica, a ação do poder local tem sido ainda bastante tímida. $\mathrm{Na}$ verdade, é a instância estadual de governo que vem demonstrando uma performance mais ativa nesse campo, gerando até algumas distorções principalmente no campo fiscal, configurando um processo de disputa predatória entre os estados da federação. Esta problemática, que tem sido objeto recorrente do debate político, só encontrará sua solução com a aprovação de uma ampla reforma tributária. $\mathrm{Na}$ área social, diferentemente, muda-se consideravelmente o status da esfera local, bem como as exigências sobre seu desempenho frente às políticas sociais.

O fato é que a Constituição Federal de 1988 definiu um novo pacto federativo que resultou em grandes transformações quanto à transferência de capacidade decisória, funções e recursos para os estados e, fundamentalmente, para os municípios. Mas também é fato que a descentralização de corte municipalizante acarretou a indefinição das competências e atribuições dos estados, criando um vazio no que se refere a medidas que atenuem as desigualdades regionais. Com efeito, tais mudanças requerem um processo de transição em que a instituição de novas relações intergovernamentais está condicionada pela capacidade de negociação de diversos conflitos e interesses, como também dependem da redefinição de objetivos, funções e reforma administrativa das agências governamentais, que agora possuem novas atribuições.

Para Abrucio et al. (1993), os princípios federativos ainda estão longe de ser implementados entre nós, seja por nossa herança assentada na crença de que o poder político deriva do centro (idéia contraposta por um regionalismo e um localismo ambíguos), seja pelo padrão atual de relação intergovernamental, centrada não na subsidiariedade, mas antes na disputa por recursos e poder político. Na visão dos autores, vivemos, neste século, ciclos de forte centralização alternados com outros mais descentralizadores.

Mas, ainda que o poder local hoje se invista de uma relevância inegável, muitos autores têm chamado atenção para a importância estratégica do poder central em estados federativos na promoção, por exemplo, de medidas regulatórias e corretoras das distorções inter-regionais.

Ao problematizar o processo de implementação desse modelo descentralizado a partir da década de 1990, Arretche (1999) conclui que é expressiva a variação do grau de descentralização entre as unidades da federação e entre as diferentes áreas de ação governamental. No entanto, apesar de avançar a diferentes velocidades, é inegável que há um processo de redefinição de atribuições e competências que modifica radicalmente o padrão centralizado de produção de políticas, especialmente nas áreas sociais.

Neste sentido, mantém-se o papel estratégico de que se investe o nível federal na execução de medidas normatizadoras e indutoras da ação do nível local na implementação de políticas descentralizadas, sem incorrer nos abusos do passado, quando o insulamento de grupos vinculados ao nível federal fez do poder excessivo da União fator de controle político dos níveis subnacionais.

Reconhece-se que com o resgate das bases federativas do país, o governo central já não dispõe dos mecanismos de alinhamento dos governos locais por meio de constrangimentos impostos pela centralização fiscal que vigoravam durante o período autoritário. Em que pesem as prerrogativas constitucionais, a divisão de responsabilidades e atribuições entre níveis de governo está imersa hoje nos conflitos resultantes da barganha federativa e da competitividade eleitoral democrática.

Com efeito, se os municípios brasileiros desfrutam de maior autonomia política, outras questões limitam essa mesma autonomia. O que está em jogo hoje é a capacidade da esfera municipal para gerir de forma eficiente as políticas públicas locais. Nesse sentido, a autonomia local varia na proporção da capacidade do governo local em formular e incumbir-se de politicas públicas sob a sua competência (King e Pierre apud Souza \& Blumm, 1999).

Porém, o efetivo exercício dessas novas competências está permeado por atributos locais de natureza variada, tais como capacidade econômica, grau de desenvolvimento urbano, perfil de distribuição da renda, localização geográfica, competência técnica, capacidade de governança, capital cívico, entre outros fatores.

Os estudos realizados sobre o problema têm enfatizado o sentido incremental desta capacidade de gestão. Não se trata de conceber o estágio atual como ponto de partida, a partir do qual se caminharia gradualmente para uma gestão 
ótima, democrática e eficaz. O que se põe em relevo é que se vem construindo no país uma trajetória particular e cumulativa de descentralização efetiva, que se processa em meio a um contexto no qual se redefinem competências e responsabilidades no nível legal, as quais são incorporadas diversamente pelas diferentes estruturas locais e pelos atores sociais aí atuantes, contribuindo para o amadurecimento do próprio processo em si.

Cabe lembrar que a implementação das políticas de corte social teve freqüentemente o nível local como co-participante, em geral na condição de nível executor. O que muda nas circunstâncias atuais, como vimos, é o aumento da competência dos espaços locais na definição e gestão destas políticas.

No Brasil, é consenso entre os autores que o viés centralizador se explicita em sua dimensão mais acabada nas políticas sociais. É no terreno da redefinição de competências entre esferas de governo na promoção de políticas e programas sociais que surgem com nitidez os dilemas envolvidos no redesenho do pacto federativo entre nós. Tais dilemas se apresentam na medida em que, desde suas origens no pós-30, a intervenção governamental na esfera social tem sido realizada em meio à centralização política e à concentração de poder decisório no Executivo federal.

Mais do que isso, é no contexto autoritário e centralizador dos anos 60-70 que se molda o perfil da política social no Brasil em seu sentido amplo, uma vez que até então a intervenção do Estado na questão social no Brasil teve um caráter fragmentado e com baixo índice de cobertura e frágeis aportes financeiros. Assim, para Draibe (1999), é no pós-64 que se constitui no Brasil um sistema de proteção social no seu sentido pleno.

Nesta perspectiva, o sistema de proteção social brasileiro foi moldado por um Estado com características unitárias, conformando um quadro onde o planejamento local consistia em formular projetos de solicitação de recursos para o governo federal, nos termos previstos pela agência federal encarregada da gestão de dada política social.

\section{Novos arranjos institucionais no campo da saúde a partir dos anos 90}

No caso da política de saúde em particular, estão em curso substantivas inovações que têm como marco não só o cenário da reforma do Estado, a redução de suas funções e o controle do gasto público, como também fatores internos, potencializados pela dinâmica do setor saúde e decorrentes da implementação do Sistema Único de Saúde (SUS). O aprofundamento da descentralização em direção à municipalização da saúde, particularmente intenso a partir de 1996, potencializa inúmeras inovações no tocante ao incremento da eficácia e eficiência da gestão do sistema, e à alocação de recursos, produzindo impactos diversificados seja nas condições de acesso aos diversos níveis de atenção, seja no desenho de novas modalidades de interseção entre público e privado, seja ainda no padrão de relacionamento Estado/sociedade e do incremento de mecanismos de controle social, reformulando a face do modelo de atenção em saúde como um todo.

Assim, podemos dizer que a dinâmica do processo de descentralização assume um sentido de municipalização radical, em que a esfera municipal de governo passa a assumir as funções de coordenação e gestão da política de saúde em seu território. A competência para formular e gerir a política de assistência à saúde esteve historicamente vinculada à esfera federal. Assim, hoje, os municípios se vêem diante da tarefa de gerir uma rede de serviços heterogênea e não integrada institucionalmente.

No plano legal, o processo de reforma da saúde foi regulamentado pela lei 8.080 de 19/9/90 e pela lei complementar 8.142 , de 22/12/90, que tratam das normas gerais de funcionamento do SUS, especialmente sobre as transferências intergovernamentais de recursos financeiros na área de saúde. Somente três anos após a lei orgânica é que os critérios para o repasse dos recursos do governo federal para os estados e municípios tornaram-se efetivos e sistemáticos. Isso se concretizou, através da Norma Operacional Básica do SUS 1/93. Esta NOB entrou em vigor a partir de 1994, estabelecendo responsabilidades, requisitos e prerrogativas para a gestão local (estados e municípios) do SUS, sob três modalidades: gestão incipiente, gestão parcial e gestão semiplena.

A condição semiplena deu aos municípios enquadrados nessa modalidade de gestão a efetiva governabilidade sobre os recursos e a administração da política de saúde. Nesse tipo de gestão, diferentemente das outras duas modalidades, o município assume a responsabilidade total sobre a gestão da prestação de serviços, o gerenciamento sobre toda a rede pública (exceto 
da rede estadual e federal) e o recebimento mensal da totalidade dos recursos financeiros para custeio correspondentes aos tetos ambulatoriais e hospitalares.

Sob a regulamentação da NOB/93, a descentralização caminhou a passos lentos. Até o final de 1997, 57\% dos municípios estavam enquadrados na gestão incipiente ou parcial e $2 \%$ na condição de gestão semiplena.

Em 1996, ocorre uma relativa mudança de curso do processo de descentralização da política de saúde, através da edição de uma nova NOB pelo Ministério da Saúde: a NOB/96, que promove o fortalecimento do papel dos estados, imprimindo maior relevância à coordenação regional do SUS. Além disso, consta do texto desta NOB estratégias para a efetivação de uma reorganização do sistema, a partir da priorização da atenção básica de saúde. A NOB/96 só passa a vigorar efetivamente a partir de 1998.

A NOB/96 também altera as modalidades de gestão local do SUS, que passam a ser apenas duas: plena da atenção básica e plena do sistema de saúde. Na primeira modalidade, os municípios passam a responder totalmente pela assistência ambulatorial, pelas ações básicas de vigilância sanitária e epidemiológica e pela gerência de todas as unidades básicas de saúde existentes na região. $\mathrm{Na}$ segunda modalidade, os municípios, além da atenção básica, passam a responder integralmente por todas as ações referentes aos serviços do SUS em sua área de abrangência, inclusive a oferta de procedimentos de média e alta complexidade tecnológica.

A partir de 1998, há uma alavancagem importante do processo descentralizador. Hoje, dos 5.506 municípios brasileiros, 97,04\% encontram-se enquadrados em alguma das duas modalidades de gestão normatizadas pelo $\mathrm{Mi}$ nistério da Saúde: 88, 07\% (4.849 municípios) estão habilitados na condição Plena de Atenção Básica e 8,97\% (494 municípios) na condição de Plena do Sistema Municipal.

Com efeito, do ponto de vista da implementação da agenda reformista definida para toda a área social, há um reconhecimento de que apenas a política de saúde foi efetivamente reformada, constatando-se o modesto saldo das mudanças e inovações nas outras áreas, apesar das alterações propostas.

Na perspectiva de Arretche (1999), o avanço da política de saúde no seu processo de reforma, essencialmente no tocante à descentralização na prestação de serviços, justifica-se devido ao elevado grau de consenso que a municipalização da saúde obteve na agenda de reformas na área social. Ademais, a coalizão pró-reforma na área sanitária é fortemente articulada e estável, sendo capaz de gerar pressão local pela adesão municipal ao SUS. Também a própria flexibilidade do desenho da descentralização, que contempla distintas modalidades de adesão, facilita a neutralização de possíveis resistências das administrações locais, derivadas dos custos financeiros a serem assumidos com a gestão dos serviços.

Mas para Draibe (1999), a agenda de reformas no campo social depara-se, a partir da metade da década de 1990, com um ambiente político muito complexo, perpassado pelo ajustamento econômico, pela complementação das reformas institucionais e pelo processo de consolidação da democracia. Isto posto, em que pese o inequívoco avanço da reforma da política de saúde na sua dimensão organizacional, na qual a descentralização é um exemplo, vários problemas e desafios se interpõem ao aprofundamento da reforma. Os principais problemas apontados pela autora são: as distorções e ineficiências do investimento, acarretando a implantação incompleta de redes intermediárias e básicas de serviços, o que sobrecarrega e compromete a efetividade do sistema hospitalar; a ineficiência, mas principalmente a ineficácia dos recursos; um modelo assistencial fundado na livre demanda, do qual estão ausentes os princípios de adscrição de clientela e de identificação de porta de entra$d a$; as antiquadas e inadequadas organização $e$ gestão do sistema e de suas unidades organizacionais.

As pesquisas empíricas têm mostrado, não obstante o avanço do processo descentralizador setorial, a heterogeneidade de experiências quanto às mudanças nos sistemas locais de saúde. A análise do processo de implementação tem evidenciado que, em muitos casos, o repasse da gestão da política de saúde à esfera municipal esbarra na precariedade da estrutura administrativa do município e, particularmente, da estrutura burocrática voltada à prestação de serviços de saúde, não sendo raros os exemplos em que a própria montagem dessa estrutura administrativa coincide com o momento em que o município assume a gestão da rede de serviços.

A mudança na alocação de recursos advinda da implementação da descentralização no setor da saúde não tem sido suficiente para modificar o padrão de desigualdade no acesso aos bens e serviços de saúde, uma decorrência da própria face heterogênea do país. Ou seja, os municípios situados nas regiões e estados mais desenvolvi- 
dos tendem a reunir os requisitos básicos necessários à assunção da gestão descentralizada e ao desenvolvimento de ações mais eficientes visando à otimização dos resultados e à maximização na utilização de recursos disponíveis. Isso porque as localidades mais ricas têm em geral mais capacidade técnica e gerencial, bem como maior aporte de recursos advindos da sua capacidade de arrecadação fiscal. Assim, a experiência recente de descentralização municipal vem demonstrando a institucionalização de inúmeras modalidades de organização dos sistemas locais, originadas da combinação entre normas institucionais do SUS e as singularidades sociopolíticas locais.

Na visão de Levcovitz (1997), a autonomia política dos municípios e a ausência de uma definição clara da hierarquia e dos papéis a serem desempenhados por cada instância de governo conferem grande complexidade às negociações em torno da descentralização do sistema de saúde. $\mathrm{O}$ forte estímulo à municipalização contradiz a obrigatoriedade da hierarquização e da regionalização da rede de serviços, tendo em vista que, em face da reduzida amplitude populacional da maioria dos municípios brasileiros, é impossível, e mesmo não seria racional, organizar, em cada um deles, um sistema que contenha os diversos níveis de atenção (primária, secundária e terciária). Apenas um percentual pequeno dos municípios brasileiros tem porte populacional que justifique a oferta de serviços em todos os níveis.

Este fato caracteriza, para aquele autor, a insuficiência dos dispositivos legais para definir as estratégias concretas de implementação da reforma da política de saúde, acerca da qual a ênfase dos discursos descentralizadores contrasta com a ausência de prioridade atribuída à construção de instrumentos e mecanismos operacionais que dêem suporte à descentralização do SUS.

Nessa medida, o debate setorial tem como um de seus consensos que, ao lado do processo de municipalização, é imperativo desenvolver estratégias que articulem as reformas dos sistemas locais a iniciativas de cunho regional, tal como proposto na Norma Operacional de Assistência à Saúde (NOAS) 1/2001. As atuais experiências de formação de consórcio expressam formas alternativas de arranjo regional. Com efeito, sem a efetiva coordenação e planejamento regionais, corre-se o risco de que o processo de descentralização se distancie dos objetivos de eqüidade em saúde.
A criação de diferentes fóruns deliberativos - as Comissões Intergestoras e os Conselhos Representativos - permitiu, na visão de Almeida et al. (1999), a construção de uma arena setorial ampliada, que tornou complexo e politizou o processo decisório. Essa nova estrutura organizacional tem exacerbado os conflitos entre os diferentes projetos que buscam institucionalizar suas demandas e, ao mesmo tempo, tem possibilitado a articulação e o fortalecimento do debate sobre a operacionalização do SUS.

Este talvez seja não só o mais importante legado do processo de descentralização em curso, mas também o que contribui para sua continuidade e amadurecimento - a emergência dos atores articulados aos diferentes níveis de poder à cena setorial. É certo que o peso relativo desses agentes é diferenciado, mas a nova estrutura decisória setorial tende a modificar a forma de distribuição dos consideráveis recursos (embora não suficientes) alocados no setor de saúde. Esse processo afeta distintos interesses e gera continuamente novas demandas, dando visibilidade a novos atores e a novos procedimentos de decisão política.

A entrada em cena de novos atores sociais vinculados à esfera municipal a partir da descentralização político-financeira em curso é um fator que contribui para a revitalização da arena política da saúde. Tal realidade difere do modelo implementado nas décadas anteriores, quando os arranjos político-clientelistas entre os setores com acesso privilegiado à esfera decisória se davam no espaço circunscrito da esfera federal.

Este novo contexto tem requerido dos outros níveis de governo - federal e estadual uma grande capacidade de regulação destinada a estabelecer as normas gerais para o funcionamento do sistema, bem como fiscalizar o seu cumprimento. Esses entes estatais, por um lado, deixam de se colocar como prestadores diretos de serviços, agora a cargo dos municípios, e passam à função de reguladores e coordenadores gerais do sistema.

No que concerne aos governos estaduais, estas funções estiveram amplamente ausentes de suas agendas, bem como de sua ação concreta. Os estados (alguns mais que outros) não foram capazes de se reorganizar internamente para desempenhar as suas novas funções. Ao contrário, se mantiveram paralisados com a aceleração do processo de transferência direta de recursos para os municípios e a diminuição do seu papel de intermediário da relação município/governo 
federal. Só recentemente, com a explicitação das gritantes disparidades entre as realidades dos sistemas locais de saúde, é que a problemática da função de coordenação regional que cabe aos governos estaduais vem sendo tematizada e tem redundado em algumas medidas concretas nesta direção, das quais a NOAS é um exemplo. Esta Norma explicita em seu texto mecanismos para a reversão do "municipalismo" radical em curso e retoma o fortalecimento do papel da esfera estadual como instrumento eficaz contra os desequilíbrios intermunicipais.

Quanto ao nível federal, a atuação do Ministério da Saúde tem sido de forte presença na cena setorial, gerando as condicionalidades e regras para o financiamento da atenção à saúde prestada pelos governos municipais. Para alguns analistas, o nível central com suas medidas fortemente indutoras tem "formatado" o desenho dos sistemas municipais, privilegiando um determinado modelo assistencial assentado sobre a atenção básica e sobre determinados programas definidos como prioritários pelo ministério e que são objetos de incentivos financeiros atraentes para o nível local, como as ações do Pacs (Programa de Agentes Comunitários de Saúde) e do PSF (Programa de Saúde da Família).

Por outro lado, tais programas são plenamente justificáveis tanto do ponto de vista do modelo de assistência hoje vigente e sua questionável eficácia, quanto do ponto de vista do perfil socioeconômico do país e as estratégias possíveis para superação dos atuais indicadores sociais e de saúde.

Em certos casos, a execução de determinados programas obedece a lógicas totalmente desvirtuadas do ponto de vista da racionalidade e resolutividade das ações propostas. Tais experiências expressam duas problemáticas fundamentais e interligadas: 1) a pouca tradição do poder político local em elaborar (ou neste caso readequar) políticas e programas voltados a responder de forma racional às demandas em seu território; e 2) a fragilidade do ponto de vista da capacidade de gestão da esfera local.

Desta forma, reforça-se o caráter de longo prazo que define um processo de descentralização, o qual requer uma capacitação progressiva de poderes locais e regionais, obedecendo a ritmos e lógicas distintos, ditados por diferenças regionais e pela existência de políticas indutivas implementadas pelo nível central. Neste sentido é que se reforça a necessária gradualidade $\mathrm{e}$ flexibilidade de que se deve investir no processo descentralizador como um processo de longo prazo, que inclui a capacitação crescente dos poderes locais como forma de torná-lo efetivo.

A nosso ver, o aprofundamento da descentralização no campo da saúde desponta como uma das estratégias metodológicas mais eficazes para examinar os efeitos concretos das mudanças em curso na área e recuperar o nível municipal com espaço de formulação e operacionalização de políticas setoriais, onde novos atores aparecem e redefinem tanto os espaços decisórios como a própria agenda da saúde. Portanto, é no nível do município que são tomadas decisões fundamentais em termos de alocação de recursos para a assistência à saúde. Nesse nível se reafirmam, ou não, decisões sobre a ampliação da capacidade instalada, o aumento da oferta de serviços, o modelo assistencial, a recuperação da rede de atenção à saúde (sucateada em quase toda sua extensão), a implementação de determinados programas sanitários priorizados pelo governo federal, o perfil e a qualidade do atendimento prestado, a distribuição espacial desses serviços, a contratação e capacitação de profissionais para o setor, etc. Neste sentido, é imprescindível que se privilegie a metodologia de estudo de caso para se compreender os desdobramentos atuais do SUS.

\section{Atores políticos no cenário local}

Como vimos, no contexto da chamada nova institucionalidade das políticas sociais, a discussão acerca da temática do poder local adquire destaque em face da constituição de novos atores sociais e do revigoramento do processo de decisão política no âmbito do município. Assim, ao tratar de analisar a produção da política de saúde nos municípios, é também relevante compreender as relações que se estabelecem entre Executivo e Legislativo, dimensionando o peso e o grau de autonomia que tais poderes detêm no processo de decisão política e institucional.

Em outras palavras, considera-se que a compreensão da forma de produção da política de saúde no nível local passa necessariamente pela investigação das relações estabelecidas entre diversos atores sociais, tais como executivo, legislativo, gestores locais, Conselho Municipal de Saúde, prestadores de serviços privados e usuários, dentre outros.

Couto e Abrucio (1995) salientam que as relações executivo/legislativo no país, a despeito das peculiaridades de cada esfera de governo, 
têm sido pautadas pela predominância do executivo no processo de produção de políticas governamentais. Nessa situação, o legislativo não cumpre adequadamente sua função dentro do processo de governo, que seria a de produzir políticas governamentais em acordo com as demandas sociais e de fiscalizar as ações do executivo. Estes autores diferenciam a conformação da relação entre estes poderes nos municípios de pequeno e médio porte das capitais e grandes cidades. Nos primeiros, verifica-se a presença de um "executivismo", o que demonstra forte assimetria entre o poder do executivo frente ao legislativo. Já nas capitais e grandes municípios, dada a grande complexidade socioeconômica e política, tem-se, como conseqüência, o aumento dos conflitos de interesses, o que faz com que diversos atores sociais se articulem de forma mais autônoma. Relativiza-se, dessa forma, a hipertrofia do executivo tal como verificada nas pequenas e médias cidades e a Câmara de Vereadores adquire maior relevância no processamento de demandas sociais.

Isso não quer dizer que o poder do prefeito não seja importante, principalmente porque os vereadores precisam dos recursos controlados pelos prefeitos para conseguirem sua reeleição. Tal situação configura um panorama de extrema complexidade política e institucional, em que o nível de tensão varia de acordo, certamente, com a composição do executivo e do legislativo em diferentes momentos.

Um dado importante a ser observado nesse contexto é a estratégia adotada pelo executivo para proceder às negociações visando obter maioria parlamentar. De outro lado, os autores citados também registram que fatores exógenos ao sistema de governo influenciam sobremaneira a conformação do relacionamento executivo-legislativo. Nesse caso, de acordo com a particularidade do município e da conjuntura, cada cidade terá uma dada moeda de troca considerada principal na negociação entre tais poderes.

Do ponto de vista da constituição do poder local e sua capacidade de produzir políticas de saúde no âmbito do município, não se pode desconsiderar o papel atribuído ao Conselho Municipal de Saúde.

Os conselhos municipais de saúde passaram a ser elementos-chave no contexto da descentralização da saúde, na medida em que os governos municipais têm ampliado seu papel no sistema, colocando sob âmbito do município, e, portanto, ao alcance do conselho, o comando do sistema naquele nível de governo. A discussão em torno dos conselhos municipais se torna assim relevante uma vez que os mesmos são visualizados como canal institucionalizado e definido em lei para o exercício do controle social, podendo constituir-se, ou não, em canal para os confrontos das relações de força, concepções e interesses políticos em nível local.

As análises sobre os conselhos municipais de saúde têm demonstrado que a institucionalização destas instâncias inaugura novas formas de gestão local nunca antes vividas por estados e municípios brasileiros. São, assim, processos relativamente recentes, introduzindo inovações e impactos diversos em cada localidade.

No entanto, é forçoso constatar que a construção deste novo lugar de fazer política esbarra com freqüência em atores e interesses tradicionais no cenário local, convivendo com certos vícios elitistas e clientelísticos que se revelaram em traços de cooptação de lideranças locais.

Neste sentido, a exemplo das tendências mais gerais, as relações que se estabelecem entre os diferentes atores no cenário local, tais como as intermediações executivo/legislativo, bem como a atuação dos conselhos municipais de saúde, espelham e são limitadas pelas formas de representação de diversos interesses e de como esses mesmos interesses se articulam no plano local.

Com efeito, após mais de uma década de implementação da descentralização da política de saúde, faz-se mister qualificar e dimensionar os limites, impasses e alcance da municipalização à luz das experiências em curso, tendo em vista que o nível municipal coloca-se indubitavelmente hoje como espaço de formulação e operacionalização de políticas de saúde.

\section{O caso de São Gonçalo (RJ): dilemas atuais da implementação das políticas locais de saúde}

Se os anos 90 são marcados pela consolidação do processo de descentralização municipal da saúde no país, é preciso considerar, no entanto, que este processo teve cursos e impactos diferenciados, conforme a realidade de cada local.

No caso do município de São Gonçalo, a assinatura do convênio de municipalização se deu em 1989, momento em que a cidade começava a viver uma nova fase política. À época, o panorama político local era favorável à municipalização em função da eleição de Edson Ezequiel (1989-1992), em 1988, para a prefeitura de São Gonçalo. A eleição do novo prefeito, através de uma coalizão liderada pelo PDT, representou uma ruptura com a tradição conservadora que durante muito tempo foi dominante em São 
Gonçalo, marcada por seu caráter populista, significando, em tese, dentro da história política municipal, uma direção mais progressista na condução da política local. Nesse contexto, a melhoria das condições de saúde se constituía numa das plataformas de campanha do novo prefeito, vindo ao encontro das demandas expressas durante a 1a Conferência Municipal de Saúde, ocorrida em 1987.

Ao analisar a gestão descentralizada da saúde em São Gonçalo, é fundamental dimensionar o impacto desse processo na reorganização da rede de serviços, tendo como referência a composição dos serviços em termos da quantidade e qualidade da oferta de cuidados, como também o padrão de referência e contra-referência entre os níveis de assistência do sistema local de saúde e municípios vizinhos.

Com a municipalização, a prefeitura local, além de se responsabilizar pela gestão dos estabelecimentos de saúde já existentes, investiu na criação de novas unidades básicas de saúde, finalizou a construção de mais dois postos de assistência médica e procurou aumentar a escala tecnológica dos hospitais e dos prontos-socorros, conferindo a essas unidades uma maior especialização comparativamente à situação anterior.

Com a municipalização, o setor de saúde de São Gonçalo passou, de fato, por algumas mudanças, decorrentes das estratégias de indução do Ministério da Saúde ao longo dos anos 90 vis-à-vis às especificidades locais. Um dos efeitos desse processo foi a estruturação da própria secretaria municipal de saúde, que, adequando-se às novas demandas gerenciais, alcançou grande projeção no próprio âmbito do governo municipal. Além disso, houve uma grande ampliação do número de unidades de atenção básica, a implantação de vários programas de saú- de e a contratação de profissionais de diversas especialidades através da realização do primeiro concurso público do município. As alterações na composição da rede de serviços podem ser observadas na tabela 1.

Com base na tabela 1 , verifica-se que a decisão política dos gestores locais foi investir prioritariamente na expansão da rede básica de forma a ampliar a oferta da atenção primária para inúmeras áreas que se encontravam desprovidas de tais serviços.

Tal iniciativa reflete uma preocupação com a disponibilização espacial dos serviços básicos de saúde como condição sine qua non para facilitar o acesso e ampliar a cobertura dos serviços de saúde e, conseqüentemente, impactar a situação de saúde da população. De fato, hoje o município de São Gonçalo conta com uma rede de serviços de "atenção primária" distribuídos em toda a extensão de seu território.

Ressalta-se que antes da municipalização havia duas áreas (2o e 3o distritos) do município que não eram cobertas por qualquer tipo de serviço de saúde. Dessa forma, a população residente nessas áreas tinha que buscar assistência médica no centro da cidade, onde se concentrava a oferta de serviços públicos e privados contratados. Vale dizer que era bastante expressiva a oferta de serviços ambulatoriais contratados da rede privada no período anterior à municipalização, serviços esses que gradualmente foram sendo descredenciados em virtude da própria expansão da rede pública de serviços básicos. $\mathrm{O}$ mesmo não acontece com os serviços mais especializados, uma vez que o investimento público (seja municipal ou estadual) nesse nível de atenção não foi, e ainda não é, suficiente para atender à demanda local. Nesta direção, o que se verifica é apenas um pequeno investimento, face

Tabela 1

Composição da rede de serviços públicos de São Gonçalo em 1989 e 2000

\begin{tabular}{lccl}
\hline Tipo de Serviço & $\mathbf{1 9 8 9}$ & $\mathbf{2 0 0 0}$ & Natureza \\
\hline Hospital geral & 1 & 2 & Municipal e Estadual \\
Hospital infantil & 1 & 1 & Municipal \\
Pronto-socorro & 2 & 2 & Municipal \\
Posto de assistência médica & 3 & 5 & Municipal \\
Centros e postos de saúde & 5 & 5 & Municipal \\
Minipostos de saúde & 2 & 32 & Municipal \\
PSF (módulos) & - & 1 & Municipal \\
Serviço pronto atendimento & - & 2 & Municipal \\
Total & 14 & 50 & \\
\hline
\end{tabular}

Fonte: Secretaria Municipal de Saúde de São Gonçalo - RJ, 2000. 
às necessidades locais, em termos de ampliação do número de leitos públicos, criação de Unidades de Terapia Intensiva (UTI) e implantação de certos serviços de cirurgia nos dois hospitais municipais e nos prontos-socorros.

Encontra-se também no município um grande número de serviços privados de saúde, contratados ou conveniados ao SUS e ainda serviços de apoio diagnóstico. $\mathrm{O}$ setor privado responde por $87 \%$ do total de leitos do município, mas, a exemplo do setor público, são de baixa complexidade, o que confirma que o município ainda carece de uma unidade de grande porte. O déficit de oferta de serviços mais especializados faz com que a população continue a buscar atendimento nos municípios de Niterói e Rio de Janeiro.

Atualmente, São Gonçalo encontra-se na gestão plena de atenção básica (NOB/96), uma vez que o município não conseguiu reunir as condições exigidas para a habilitação na modalidade de gestão plena do sistema. Para o poder municipal assumir a gestão da atenção hospitalar seria necessária uma base de sustentação por parte das esferas federal e estadual no sentido de investir no aumento do número de leitos públicos e serviços de apoio diagnóstico. Tal situação configuraria um cenário marcado por um maior equilíbrio entre a oferta de serviços públicos e contratados no município. A atual predominância da oferta de serviços privados contratados pelo SUS tem como efeito perverso a fragilização da gestão pública nos processos de negociação e regulação do setor privado.

Se a análise dos rumos da assistência médica em São Gonçalo mostra uma significativa expansão da rede básica após a municipalização, há que se considerar que o município, contudo, ainda não conseguiu enfrentar o déficit de serviços mais especializados, seja em nível secundário ou terciário. Isso pode ser observado pela frágil diferenciação entre os perfis assistenciais das unidades, como também pela ausência de uma unidade de grande porte no município.

Além disso, as unidades básicas, ou seja, a porta de entrada do sistema, apresentam uma baixa capacidade resolutiva em virtude da dificuldade de fixar profissionais, principalmente em áreas mais distantes. Muitas dessas unidades não funcionam em todos os turnos, agregandose a isso a dificuldade de os gestores controlarem o cumprimento da carga horária, principalmente no que se refere ao profissional de medicina.

Com efeito, é a não-conformação de uma rede hierarquizada, em termos de níveis de com- plexidade da atenção à saúde, que faz com que $65 \%$ dos casos que chegam aos serviços de emergência sejam atendimentos de caráter ambulatorial. A persistência desse fenômeno, característico do modelo médico privatista dos anos 70 , além de gerar ineficiência, não promove mudanças desejáveis em termos do modelo assistencial propugnado pelo projeto SUS. Um exemplo disso é a não concretização da perspectiva da integralidade e resolutividade face à inexistência de uma vinculação da população a um determinado serviço e equipe de saúde.

De fato, a reforma do setor saúde no município não conseguiu sequer imprimir a lógica da racionalização econômica, na medida em que a porta de entrada do sistema ainda se dá via emergência o que, obviamente, eleva os custos da atenção médica.

Tendo em vista que a rede de serviço não se constitui como tal em virtude da inexistência de serviços que se estruturem hierarquicamente em acordo com a densidade tecnológica, há como conseqüência uma definição apenas formal dos fluxos de referência e contra-referência. Com base nisso, prevalece no município a demanda espontânea aos diversos estabelecimentos de saúde, não funcionando, na prática, a adscrição de clientela, a referência e contra-referência.

Com a municipalização, a própria secretaria municipal de saúde passou por uma reestruturação de forma a adequar-se às novas demandas gerenciais. Pode-se mesmo dizer que este foi um dos efeitos provocados pela descentralização da saúde em todo o país. Entretanto, no caso específico do município de São Gonçalo, apesar da continuidade administrativa, já que esse mesmo grupo político liderado pelo PDT mantevese no poder durante 12 anos, o sistema de saúde local não conseguiu superar os traços mais perversos inscritos no modelo tradicional de organização dos serviços.

Nas últimas eleições municipais de 2000, o PMDB, coligado com outros partidos, assume o executivo local com a promessa de atender a um rol de demandas sociais não respondidas pelos governos pedetistas anteriores. No contexto desta nova composição política, a saúde adquire mais uma vez papel de centralidade, traduzida, principalmente, na escolha de uma profissional de reconhecida capacidade técnica e política no campo da saúde coletiva para ocupar o cargo de secretária municipal de saúde. A SMS passa então a ter como tarefa principal a implantação do Programa de Saúde da Família (PSF) no muni- 
cípio, programa que foi carro-chefe da campanha eleitoral do atual prefeito.

Vale dizer que o PSF formulado pelo Ministério da Saúde ganha impulso em nível nacional a partir de 1998, em razão principalmente de diversos mecanismos de indução definidos pelo governo federal. Dentre os estímulos para que os municípios implementem o PSF, podem-se destacar os de caráter financeiro. Assim, o PAB (Piso de Atenção Básica), forma de financiamento da atenção básica através de repasse do Fundo Nacional de Saúde para o Fundo Municipal de Saúde, vem compor um conjunto de incentivos político-financeiros destinados, dentre outras questões, a disseminar as ações do PSF e Pacs em todo território nacional. O PAB é repassado pelo governo federal diretamente aos municípios sendo este constituído por uma parte fixa per capita e outra variável. É exatamente na possibilidade de aumentar os recursos repassados para o município que se encontra o potencial de extensão do PSF nos municípios brasileiros. A indução, com ênfase no incremento do financiamento das ações de saúde, constitui questão crucial no cálculo político de prefeitos quanto ao processo decisório sobre as ações de saúde a serem implantadas nos municípios. Para o Ministério da Saúde, o PSF é um programa estratégico para reorientar o modelo assistencial com a perspectiva de superar os dilemas relacionados à falta de resolutividade da atenção básica, bem como ampliar o acesso aos cuidados de saúde.

O princípio ordenador deste programa é a vinculação de uma equipe de saúde a um certo número de famílias residentes em uma determinada área. Nesta perspectiva, o cadastramento e o acompanhamento da população são fundamentais para o desenvolvimento das ações previstas. De acordo com a concepção do ministério, o PSF deve ser a porta de entrada do sistema de saúde, devendo estabelecer relação com a rede de serviços de maior complexidade.

A partir de um diagnóstico que assinala a existência de diversos problemas da rede pública de saúde no município, a nova gestão da Secretaria Municipal de Saúde define pela implementação do PSF como alternativa de reorganização dos serviços, buscando fundamentalmente alcançar patamares adequados de cobertura e resolutividade do sistema local de saúde.

Com base nesse objetivo, e dada a imensa precariedade das condições sociais da maioria da população, o desenho do PSF em São Gonçalo adquire características de universalidade, co- brindo, inicialmente, $64,7 \%$ (correspondendo aos 1 o e $3 \underline{o}$ distritos) dos residentes.

A proposta de implantação do PSF em São Gonçalo surge como uma inovação comparativamente às diversas experiências em curso no país, por tratar-se de um município de grande porte localizado em região metropolitana, com características marcadamente urbanas e com indicadores epidemiológicos e sociais dramáticos. Essa realidade também se confirma nos indicadores de saúde, tais como taxas significativas de prevalência de hanseníase e tuberculose, baixa cobertura vacinal, etc., exigindo, portanto, estratégias ousadas de intervenção.

O diferencial do PSF em São Gonçalo refere-se ao fato de que a estratégia adotada foge à perspectiva de focalização comum às experiências existentes. Neste sentido, o primeiro desafio desta estratégia é o grande número de equipes de saúde da família que passou a atuar no município, somando um total de 177 equipes, o que se traduz em um contingente de mais de 1.600 profissionais. Essas equipes são constituídas por um médico generalista, um enfermeiro, um auxiliar de enfermagem e de quatro a seis agentes comunitários de saúde, responsáveis pelo acompanhamento das famílias em sua área de atuação, totalizando 160.023 famílias e uma população estimada em 576.085 habitantes.

Com efeito, as dimensões do programa ganham centralidade diante da fragilidade gerencial característica do município, tornando ainda mais complexa a tarefa de planejar e monitorar as ações do programa.

O segundo desafio diz respeito à precariedade da rede de serviços existente, visto que o fluxo de atendimento da população não corresponde à necessária hierarquização do sistema de saúde local, inexistindo mecanismos formais de referência e contra-referência. Diante desse quadro, o programa assume o duplo desafio de reorganizar a atenção básica e provocar a remodelagem de toda a rede de maior complexidade tecnológica, criando canais de integração entre o PSF e os demais serviços.

O PSF no município está ligado diretamente ao secretário de saúde, demonstrando a centralidade política do programa para a atual administração local. Essa forma de estruturação do programa veio, em certa medida, esvaziar politicamente a Superintendência de Saúde Coletiva, que não tem ingerência sobre o processo decisório relativo ao programa como tem sobre os demais programas existentes na rede. Vale ressaltar que antes da implantação do PSF essa 
superintendência era responsável pela gestão de toda a atenção básica do município.

Com certeza, essa opção pode dificultar a integração entre o PSF e a rede de serviços já existente, caso não se efetivem mecanismos gerenciais capazes de promover a articulação entre o PSF e os demais programas de saúde.

Vale destacar que o sucesso do PSF em qualquer município depende, em grande medida, da capacidade de resolutividade dos serviços de média e alta complexidade tecnológica para dar seguimento ao processo de assistência à saúde. Caso contrário, o risco é de que o PSF se restrinja a uma cesta minimalista, instaurando um cardápio básico no que diz respeito à oferta de serviços de saúde e distanciando-se da perspectiva de imprimir uma nova lógica ao modelo de atenção à saúde no nível local. Neste sentido, é fundamental não perder de vista a necessidade de elaboração de estratégias de gestão que favoreçam a conexão entre o PSF como porta de entrada do sistema e as outras unidades assistenciais do sistema local de saúde.

Em muitos casos, a implantação do PSF traz novas requisições ao modo de funcionamento das demais unidades assistenciais, exigindo um novo patamar de resolutividade, cobertura e efetividade. Em São Gonçalo, esta é uma tarefa extremamente complexa, dada a notória fragilidade gerencial destas unidades, que não se organizam como um sistema hierarquizado de saúde.

Para além dos efeitos não previstos, inerentes à implementação de uma dada política, no caso do PSF em São Gonçalo, a exoneração da secretária municipal de Saúde, em setembro de 2001, vem produzindo uma grande imprevisibilidade quanto aos rumos do programa. Na verdade, o que se verifica é a influência da tradição política local, já que um vereador com forte ligação com o setor privado da saúde assume o cargo de secretário municipal da Saúde.

Ainda que este novo gestor dê continuidade ao processo de implantação do PSF como política prioritária de governo, o alcance do programa em termos de reorientação do modelo assistencial esbarra na magnitude do setor privado no município, seja ao nível da oferta dos serviços, seja no tocante a seu poder de influência no processo decisório.

Portanto, o alcance do PSF na organização da atenção à saúde, no que pesem as estratégias de indução desenhadas pelos níveis supranacionais, depende, em grande parte, do processo de intermediação de interesses no nível local, dan- do lugar a retraduções diversas do modelo proposto pelo Ministério da Saúde.

Quanto ao município de São Gonçalo, não se pode esquecer a tradição clientelístico-populista dos períodos anteriores e a forma de constituir e tratar o poder local. Tais questões têm, certamente, influência direta na arena decisória da política local de saúde nesse município, delineando, dentre outras questões, o relacionamento executivo-legislativo, bem como constrangendo o poder do Conselho Municipal de Saúde na formulação da política, o que seria, em tese, sua função precípua.

Vale ressaltar que, a Câmara de Vereadores desse município vem exercendo, ao longo de diversas gestões, papel importante no processo de intermediação de interesses na área da saúde. Diversos vereadores vêm se elegendo com base em campanhas que os vinculam a benfeitorias e promessas de melhorias relacionadas à oferta de serviços de saúde. A situação de precariedade socioeconômica e a ineficiência do sistema de saúde local constituem terreno fértil para o desenvolvimento de práticas clientelísticas, fazendo da saúde moeda de troca relevante no processo de negociação política, ao mesmo tempo em que essas práticas clientelísticas perpetuam a vulnerabilidade social, constituindo, assim, um círculo vicioso.

Com efeito, faz parte da tradição política local o uso clientelístico de cargos e bens públicos, através da indicação para postos-chave dentro da estrutura gestora municipal. No caso da saúde, uma marca freqüente tem sido a nomeação dos gestores das unidades básicas, muitas vezes sem possuir a qualificação técnica necessária, em função da indicação de vereadores cuja base eleitoral localiza-se nas comunidades onde estas unidades estão situadas.

A primeira gestão da saúde no atual governo buscou inibir a interferência da classe política local, especialmente do legislativo, ao tentar tomar para si a tarefa de indicar os gestores das unidades básicas de saúde, considerando também os critérios de ordem técnica. Tal situação gerou uma série de conflitos na arena política da saúde, enfrentando, até, resistências por parte de algumas comunidades locais.

Quanto à atuação do Conselho Municipal de Saúde em São Gonçalo, constatou-se que, durante longo período, as reuniões do conselho praticamente se resumiam a discutir o que é denominado na pauta como "processos pendentes”. Tais processos dizem respeito a solicitações de medicamentos, exames complementares e 
procedimentos de média e alta complexidade encaminhados por usuários à Secretaria Municipal de Saúde. Com isto, o conselho cai num burocratismo que dificulta o exercício do seu potencial político.

Portanto, é preciso reconhecer que o alcance e o conteúdo da ação política dos conselhos municipais estão intrinsecamente relacionados à existência de um conjunto de mecanismos próprios de uma institucionalidade democrática. Num contexto onde estes mecanismos são frágeis e predominam os traços mais perversos da tradição política local, verifica-se que a gestão da esfera pública e a eficácia das políticas governamentais acabam subsumidas pelo particularismo e pelo clientelismo característicos do modo de produzir política no nível local.

\section{Considerações finais}

O estudo em questão corrobora a idéia de que a análise de realidades concretas é condição para se estabelecerem mediações eficazes à caracterização das relações entre poder local e políticas públicas no contexto atual da descentralização do Estado brasileiro. Torna-se, assim, fundamental, compreender os dilemas que cercam o desenvolvimento da ação governamental no ní-

\section{Referências bibliográficas}

Abrucio FL et al. 1993. Descentralização e pacto federativo. Cadernos ENAP 1(1).

Abrucio FL 1996. Os barões da federação. Ed. Hucitec, São Paulo.

Almeida M et al. 1999. A reforma sanitária brasileira: em busca da eqüidade. Pan American Health Association, Washington.

Almeida MHT 1996. Federalismo e políticas sociais. In Affonso RBA \& Silva PLB (orgs.). Federalismo no Brasil: descentralização e políticas sociais. Ed. Fundap, São Paulo.

Arretche MT 1999. Políticas sociais no Brasil: descentralização em um estado federativo. Revista Brasileira de Ciências Sociais, 40.

Bezerra M 1999. Em nome das bases: politica, favor e dependência pessoal. Relume-Dumará, Rio de Janeiro.

Brasil, Ministério da Saúde 2001. Norma Operacional de Assistência à Saúde. Brasília.

Brasil, Ministério da Saúde 1996. Norma Operacional Básica 1/96. Brasília.

Brasil, Ministério d Saúde 1993. Descentralização das ações e serviços de saúde: a ousadia de cumprir e fazer cumprir a lei. Relatório Executivo. Brasília.

Couto C \& Abrucio FL 1995. Governando a cidade? A vel local, buscando identificar a constelação de instituições, agente e redes políticas que se interpenetram, moldam, orientam e/ou modificam a atuação do poder local no campo das políticas sociais.

Comparativamente a outras áreas de política social, a política de saúde tem sido alvo de fortes ações indutoras por parte do governo federal no sentido da descentralização, com repercussões particulares nos estados e municípios brasileiros.

O estudo do caso de São Gonçalo, que representa a face empírica da pesquisa, demonstra que a produção da política de saúde nessa localidade esbarra em constrangimentos caracterizados pela interconexão entre elementos intrínsecos ao próprio ordenamento do sistema local de saúde e a maneira como se conforma o poder político no município.

Nesta direção, o desafio de São Gonçalo para gerir de forma mais eficiente e democrática a assistência à saúde pressupõe, além da descentralização do próprio poder político local, através da disseminação de novos espaços de decisão, a adoção de uma conduta política em que o atendimento às demandas se processe a partir de regras enunciadas, por oposição ao uso clientelístico da política local.

força e a fraqueza da Câmara Municipal. São Paulo em Perspectiva 9(2).

Daniel C 1990. As administrações populares e democráticas em questão. Espaço \& Debates, 30.

Draibe SM 1999. As políticas sociais nos anos 90. In Baumann R (org.). Brasil: uma década em transição. Ed. Campus, São Paulo.

Levcovitz E 1997. Transição x consolidação: o dilema estratégico da construção do SUS - um estudo sobre as refomas da política nacional de saúde - 1974/1996. Tese de doutorado, Instituto de Medicina Social/UERJ, Rio de Janeiro.

Rezende FC 1997. Descentralização, gastos públicos e preferências alocativas dos governos locais no Brasil (1989-1994). Dados. Revista de Ciências Sociais 40(3).

Souza C \& Blumm M 1999. Autonomia política local: uma revisão da literatura. BIB - Revista Brasileira de Informação Bibliográfica em Ciências Sociais 48.

Zimmermann A1999. Teoria geral do federalismo democrático. Ed. Lumen Júris, Rio de Janeiro.

Artigo apresentado em 10/3/2002

Versão final apresentada em 15/5/2002

Aprovado em 19/5/2002 